\title{
Overheating threshold and its effect on time-temperature-transformation diagrams of zirconium based bulk metallic glasses
}

\author{
S. Mukherjee, Z. Zhou, J. Schroers, W. L. Johnson, and W. K. Rhim ${ }^{\text {a) }}$ \\ Division of Engineering and Applied Science, California Institute of Technology, Pasadena, California 91125
}

(Received 23 February 2004; accepted 21 April 2004; published online 28 May 2004)

\begin{abstract}
A pronounced effect of overheating is observed on the crystallization behavior for the three zirconium-based bulk metallic glasses: $\mathrm{Zr}_{41.2} \mathrm{Ti}_{13.8} \mathrm{Cu}_{12.5} \mathrm{Ni}_{10} \mathrm{Be}_{22.5}, \mathrm{Zr}_{57} \mathrm{Cu}_{15.4} \mathrm{Ni}_{12.6} \mathrm{Al}_{10} \mathrm{Nb}_{5}$, and $\mathrm{Zr}_{52.5} \mathrm{Cu}_{17.9} \mathrm{Ni}_{14.6} \mathrm{Al}_{10} \mathrm{Ti}_{5}$. A threshold overheating temperature is found for each of the three alloys, above which there is a drastic increase in the undercooling level and the crystallization times. Time-temperature-transformation (TTT) diagrams were measured for the three alloys by overheating above their respective threshold temperatures. The TTT curves for $\mathrm{Zr}_{41.2} \mathrm{Ti}_{13.8} \mathrm{Cu}_{12.5} \mathrm{Ni}_{10} \mathrm{Be}_{22.5}$ and $\mathrm{Zr}_{57} \mathrm{Cu}_{15.4} \mathrm{Ni}_{12.6} \mathrm{Al}_{10} \mathrm{Nb}_{5}$ are very similar in shape and scale with their respective glass transition temperatures, suggesting that system-specific properties do not play a crucial role in defining crystallization kinetics in these alloys. The critical cooling rates to vitrify the alloys as determined from the TTT curves are about $2 \mathrm{~K} / \mathrm{s}$ for $\mathrm{Zr}_{41.2} \mathrm{Ti}_{13.8} \mathrm{Cu}_{12.5} \mathrm{Ni}_{10} \mathrm{Be}_{22.5}$ and 10 $\mathrm{K} / \mathrm{s}$ for $\mathrm{Zr}_{57} \mathrm{Cu}_{15.4} \mathrm{Ni}_{12.6} \mathrm{Al}_{10} \mathrm{Nb}_{5}$. The measurements were conducted in a high-vacuum electrostatic levitator. (C) 2004 American Institute of Physics. [DOI: 10.1063/1.1763219]
\end{abstract}

The exceptional glass forming ability of the recently developed bulk metallic glass $(\mathrm{BMG})$ forming alloys ${ }^{1-4}$ has provided an unique opportunity to study the crystallization kinetics in the entire undercooled melt down to the glass transition temperature. One measure of glass forming ability (GFA) is the critical cooling rate to bypass the "nose" of the time-temperature-transition (TTT) curve. The shape and the position of the TTT curve in the temperature-time space is determined by the nucleation and growth mechanism. In most cases the intrinsic homogeneous crystallization is overshadowed by extrinsic influences. ${ }^{5-8}$ Reducing the extraneous effects greatly enhances the $\mathrm{GFA}^{5-8}$ and facilitates the understanding of intrinsic nucleation and growth mechanisms of BMGs. To that effect, containerless processing methods are ideal for the study of crystallization behavior because they eliminate the role of container walls as heterogeneous nucleation sites.

Three notable zirconium-based BMGs whose crystallization behavior have been studied using the containerless electrostatic levitation technique are $\mathrm{Zr}_{41.2} \mathrm{Ti}_{13.8} \mathrm{Cu}_{12.5} \mathrm{Ni}_{10} \mathrm{Be}_{22.5}$ (Vit1), ${ }^{2} \quad \mathrm{Zr}_{57} \mathrm{Cu}_{15.4} \mathrm{Ni}_{12.6} \mathrm{Al}_{10} \mathrm{Nb}_{5} \quad$ (Vit106), ${ }^{3}$ and $\mathrm{Zr}_{52.5} \mathrm{Cu}_{17.9} \mathrm{Ni}_{14.6} \mathrm{Al}_{10} \mathrm{Ti}_{5}$ (Vit105). ${ }^{9}$ The TTT curve for Vit1 was obtained using an electrostatic levitator (ESL) by Kim et al. ${ }^{10}$ with a nose temperature of $850 \mathrm{~K}$ and nose time about $50 \mathrm{~s}$. While the ESL study of Vit ${ }^{10}$ provided remarkable insights into the crystallization behavior, there are still some open questions about the underlying mechanismwhether it is intrinsic or extrinsic crystallization. Hays et al. $^{11}$ studied the undercooling behavior of Vit106 in an ESL. They obtained a partial TTT curve for Vit106 with two branches. The samples crystallized beyond a certain degree of undercooling and could not be vitrified by free cooling in the ESL. The effect of oxygen content on the TTT curve was investigated by Lin et al. ${ }^{9}$ for the Vit105 system. They ob-

\footnotetext{
a) Author to whom correspondence should be addressed; electronic mail: won-kyu.rhim@caltech.edu
}

served a drastic reduction in the crystallization times for alloys with higher oxygen content. Melting of the oxygen containing phase by higher overheating led to increase of the crystallization times. So far, the study by Lin et al. ${ }^{9}$ is the only one dealing with heterogenous influences on TTT curves of zirconium-based BMGs.

In this letter we report the pronounced effect of overheating that is observed on the undercooling behavior and the crystallization times for the three zirconium-based BMGs: Vit1, Vit106, and Vit105. TTT diagrams were measured for the three alloys by overheating above their respective threshold temperatures. A high-vacuum electrostatic levitator (ESL) was used for the processing of the samples to avoid heterogeneous nucleation induced by the container walls.

The samples were prepared from high purity starting materials in an arc melter. The glass transition temperatures $\left(T_{g}\right)$ were obtained for the three alloys using graphite crucibles in a differential scanning calorimeter at a heating rate of $0.333 \mathrm{~K} \mathrm{~s}^{-1}$. The $T_{g}$ values for Vit1, Vit106, and Vit105 are 625,682 , and $675 \mathrm{~K}$, respectively. The liquids temperatures $\left(T_{L}\right)$ for the alloys were obtained in a differential thermal analyzer at a heating rate of $0.167 \mathrm{~K} \mathrm{~s}^{-1}$. They are 993, 1115, and $1090 \mathrm{~K}$ for Vit1, Vit106, and Vit105, respectively. Samples about $15 \mathrm{mg}$ in weight were levitated in the ESL and melted using a high power continuous wave Nd-YAG laser. For undercooling experiments, the samples were allowed to free cool in vacuum (pressure $\sim 10^{-8}$ mbar) from the molten state by turning off the laser. To determine the TTT diagram, isothermal experiments were performed. Therefore, the molten sample was cooled radiatively to a predetermined temperature by turning off the laser, which was turned back on to maintain the isothermal temperature. The temperature fluctuations were within $\pm 2 \mathrm{~K}$ during the isothermal treatment for the TTT curve measurement. The temperature was measured remotely using a two-color pyrometer with a nominal sensitivity range of $650-1600 \mathrm{~K}$. A 


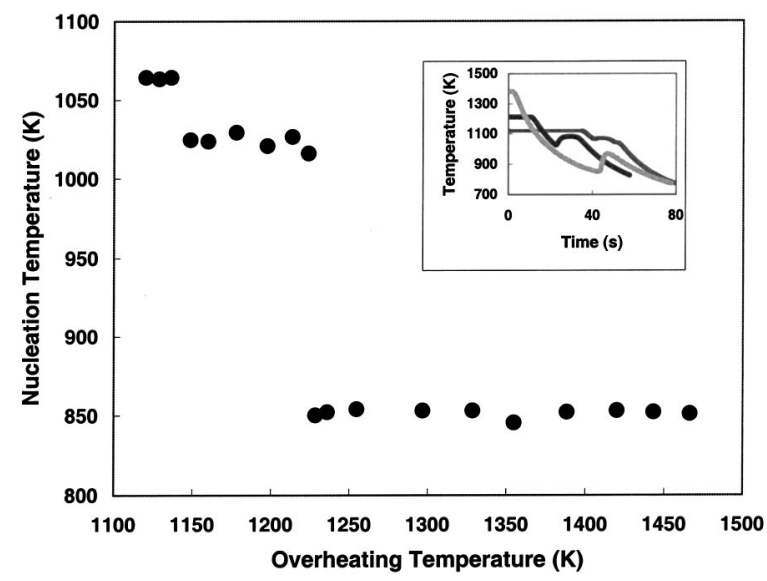

FIG. 1. Nucleation temperature vs overheating temperature for $\mathrm{Zr}_{52.5} \mathrm{Cu}_{17.9} \mathrm{Ni}_{14.6} \mathrm{Al}_{10} \mathrm{Ti}_{5}$ (Vit105). The cooling curves obtained from different levels of overheating are shown in the inset, in which the temperature at time, $t=0 \mathrm{~s}$, shows the level of overheating.

detailed description of the ESL facility is given elsewhere. ${ }^{12}$

Figure 1 is the summary of the maximum undercooling level achieved with different overheating temperatures for Vit105. The cooling curves obtained from different levels of overheating are shown in the inset. Crystallization is evidenced by recalescence, the sharp rise in temperature due to the release of the latent heat of fusion. Samples cooled from below $1140 \mathrm{~K}$ showed very small undercooling. Samples cooled from temperatures between 1150 and $1220 \mathrm{~K}$ showed larger undercooling $(\sim 60 \mathrm{~K})$ and recalesced back to the solidus temperature to form an isothermal plateau until the entire sample crystallized. A step increase in the undercooling level to a significantly larger value $(\sim 220 \mathrm{~K})$ was observed when the samples were overheated above $1225 \mathrm{~K}$. At this point, it should be mentioned that the sample has to be overheated each time above the threshold temperature of $1225 \mathrm{~K}$ to achieve deep undercooling. It is not sufficient to overheat just once for all subsequent undercooling studies.

The effect of overheating on Vit106 is summarized in Fig. 2. As the overheating temperature was raised, crystallization which initially appeared as a sharp rise in temperature, gradually reduced to small humps. Finally, for overheating above $1410 \mathrm{~K}$, the hump in the cooling curve disappeared altogether and the temperature-time profile suggests that the material solidified in an amorphous structure.

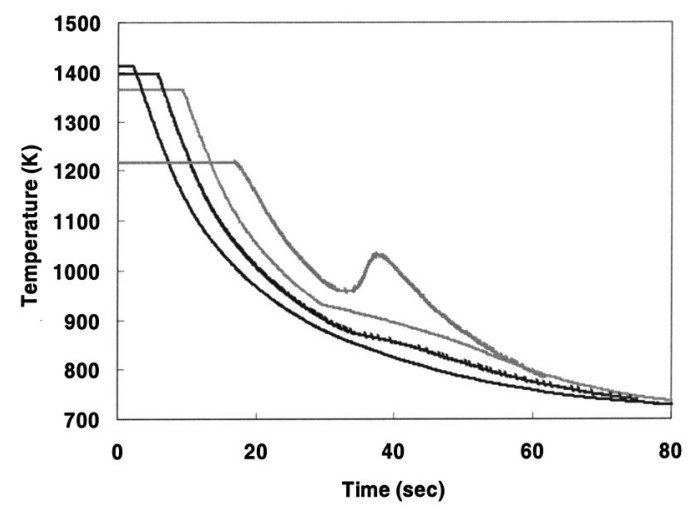

FIG. 2. The cooling curves obtained for $\mathrm{Zr}_{57} \mathrm{Cu}_{15.4} \mathrm{Ni}_{12.6} \mathrm{Al}_{10} \mathrm{Nb}_{5}$ (Vit106) with different levels of overheating. The alloy vitrifies for overheating above

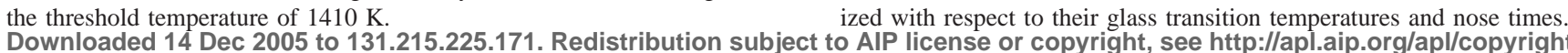

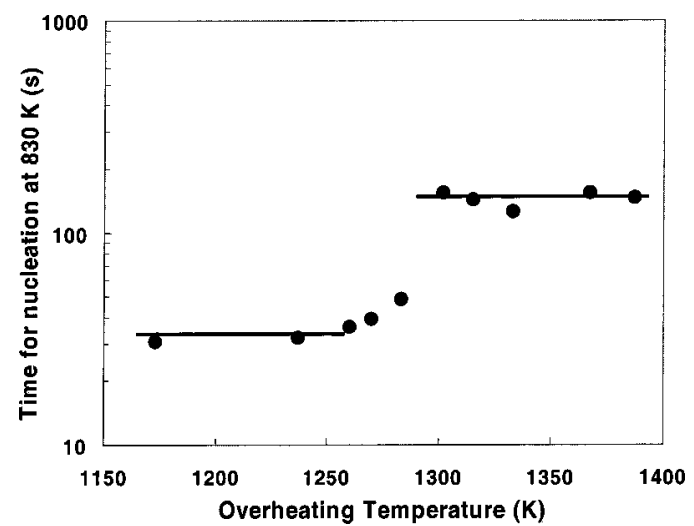

FIG. 3. Isothermal $(830 \mathrm{~K})$ annealing times until crystallization as a function of different levels of overheating for $\mathrm{Zr}_{41.2} \mathrm{Ti}_{13.8} \mathrm{Cu}_{12.5} \mathrm{Ni}_{10} \mathrm{Be}_{22.5}$ (Vit1).

To study the effect of overheating on the TTT curve for Vit1, we isothermally annealed the sample at $830 \mathrm{~K}$ (close to the nose temperature in the previous ESL study ${ }^{10}$ ) and noted the time for crystallization as a function of sample overheating. When the sample was overheated below $1250 \mathrm{~K}$, crystallization time was about $30 \mathrm{~s}$. However, the crystallization time increased to about $130 \mathrm{~s}$ for overheating above $1300 \mathrm{~K}$, as shown in Fig. 3.

After the identification of the critical overheating temperatures (1225 K for Vit105, $1410 \mathrm{~K}$ for Vit106, and $1300 \mathrm{~K}$ for Vit1), TTT curves were measured for the three alloys by cooling them from above their respective threshold temperatures. The TTT curves so measured are shown in Figure 4. The starting of the isothermal anneal time at each temperature was used as the time origin $(t=0)$ for the TTT curves. The TTT curves for Vit1 and Vit106 show the expected " $C$ " shape. For Vit1, the nose temperature and nose time are 800 $\mathrm{K}$ and $70 \mathrm{~s}$, respectively. The nose temperature is about $50 \mathrm{~K}$ lower, the nose time about $20 \mathrm{~s}$ longer, and the TTT curve is much narrower compared to the previous ESL study. ${ }^{10}$ The entire TTT curve for Vit106 was obtained with a nose temperature of $880 \mathrm{~K}$ and nose time of $5 \mathrm{~s}$. In a previous study, Vit106 could not be vitrified with the same technique. ${ }^{11}$ For Vit105, only the upper part of the TTT curve could be ob-

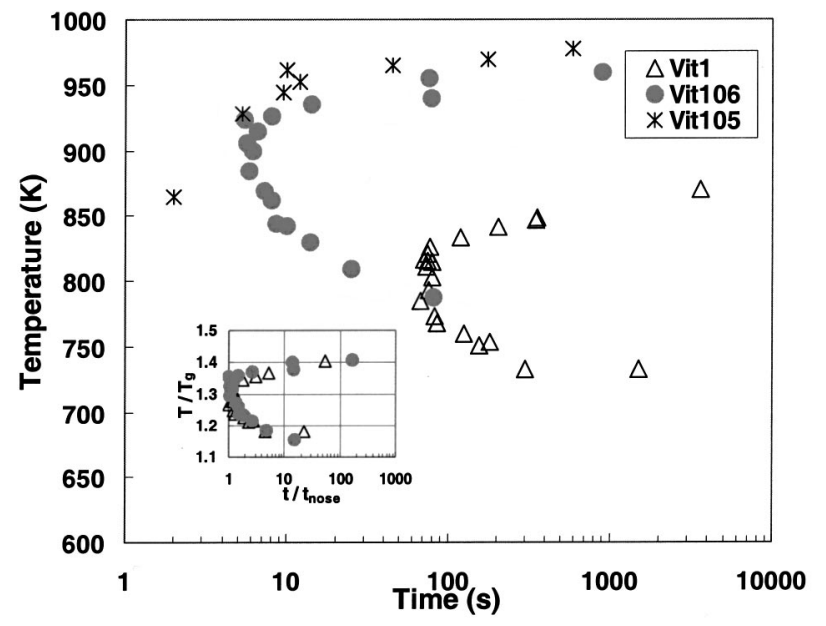

FIG. 4. TTT curves for $\mathrm{Zr}_{52.5} \mathrm{Cu}_{17.9} \mathrm{Ni}_{14.6} \mathrm{Al}_{10} \mathrm{Ti}_{5}$ (Vit105), $\mathrm{Zr}_{57} \mathrm{Cu}_{15.4} \mathrm{Ni}_{12.6} \mathrm{Al}_{10} \mathrm{Nb}_{5}$ (Vit106), and $\mathrm{Zr}_{41.2} \mathrm{Ti}_{13.8} \mathrm{Cu}_{12.5} \mathrm{Ni}_{10} \mathrm{Be}_{22.5}$ (Vit1). Shown in the inset are the TTT curves for Vit1 and Vit106 that are normalized with respect to their glass transition temperatures and nose times. 
tained even with heating of the sample above the critical overheating temperature. The samples crystallized instantly for temperatures below $860 \mathrm{~K}$.

A pronounced influence of overheating is observed on the undercooling level and the crystallization times for Vit105, Vit106, and Vit1. A threshold overheating temperature is observed, above which there is a drastic change in the crystallization kinetics. Prior to each undercooling experiment, the sample has to be heated above the critical threshold temperature. It is not sufficient to overheat once above the threshold for all subsequent undercooling cycles. This suggests that heterogeneities acting as nucleation sites are dissolved by heating above the threshold temperature. The results do not allow us to state unambiguously whether the liquid sample cooled from above the threshold temperature crystallizes in a homogeneous or heterogeneous manner. The results however do imply that the heterogeneous sites reform during crystallization of the liquid sample (dynamic heterogeneous nucleation). If the liquid is cooled from a temperature below the threshold overheating temperature the heterogeneous sites are never dissolved and induce the crystallization process (static heterogeneous nucleation). This leads to smaller undercoolings and shorter crystallization times. Static and dynamic heterogeneous nucleation, as seen in this study, was observed in different grades of pure zirconium suggesting that these are rather ubiquitous phenomena limiting the undercooling level of pure zirconium and its alloys. ${ }^{13}$

The increase in crystallization times observed in this study after heating above the threshold temperatures suggests that the TTT diagrams obtained in the previous studies ${ }^{10,11}$ do not reflect homogeneous nucleation. It does not allow us to state unambiguously that the crystallization behavior observed in this study is homogeneous, though the heterogeneous influences are reduced. A statistical analysis as suggested by Skripov ${ }^{14}$ will be carried out in the future to distinguish between homogeneous and heterogeneous nucleation. The scatter in the maximum undercooling (or the time to reach crystallization in an isothermal experiment) will be correlated with the number of potential nuclei. In a homogeneous nucleation process all atoms are potential nuclei while in the heterogeneous case, the number of nuclei is much less.

In an earlier investigation on Vit1, it was found that crystallization changes from a nucleation controlled mechanism at high temperatures to a growth controlled mechanism at low temperatures. ${ }^{15}$ Impurities acting as heterogeneous sites strongly affect the nucleation process but have negligible influence on the growth process. So reduction of heterogeneous influences will be reflected more in the upper part of the TTT curve, which is nucleation controlled. This in turn will cause the nose of the TTT curve to be at a lower temperature and shifted toward longer crystallization time. Indeed, the nose of the TTT curve for Vit1 obtained after overheating above the threshold temperature in this study is lower by $50 \mathrm{~K}$ and shifted to the right compared to previous ESL study. ${ }^{10}$

The role of oxygen content on the crystallization behavior of Vit105 was investigated by Lin et al..$^{9}$ They found that the higher the oxygen content of the alloy, the higher the overheat temperature required to suppress heterogeneous effects. The overheating effect was attributed to the melting of an oxygen containing phase. During cooling this phase nucleates at a certain undercooling and triggers the crystallization of the liquid. The high affinity of zirconium for oxygen ${ }^{16}$ suggests that the overheating effects we see for the other two zirconium alloys, namely Vit1 and Vit106, can also be explained by oxide particles acting as heterogeneous sites.

To compare the TTT curves of Vit1 and Vit106, the temperatures in the TTT curves are normalized by the glass transition temperature and time axis is normalized by the nose time of each alloy. The normalized plot is shown as an inset in Fig. 4. The nose temperatures $\left(T_{n}\right)$ for the two alloys bear a constant ratio with their respective glass transition temperatures $\left(T_{n} / T_{g} \sim 1.3\right)$. The shape of the TTT curves is very similar for the two alloys on the normalized plot. However, the nose time for Vit106 is about $5 \mathrm{~s}$ while that of Vit1 is 70 $\mathrm{s}$, which is more than an order of magnitude larger. The dynamic viscosities measured by drop oscillation technique ${ }^{17}$ show that the viscosity of Vit1 is about an order of magnitude larger than Vit106 in the range of temperature measurement of the TTT curves $\left(1.1 T_{g}<T<1.4 T_{g}\right)$. This suggests that the time for crystallization is proportional to the dynamic viscosity which may be the most important factor in determining the crystallization behavior of these alloys once the heterogeneous influences are suppressed. The critical cooling rates to vitrify the alloys as determined from the TTT curves are about $2 \mathrm{~K} / \mathrm{s}$ for Vit1 and $10 \mathrm{~K} / \mathrm{s}$ for Vit106.

This work was carried out at California Institute of Technology under a contract with the National Aeronautical and Space Administration (Grant No. NAG8-1744). The authors wish to thank Dr Haein Choi-Yim for providing the Vit1 samples.

\footnotetext{
${ }^{1}$ A. Inoue, T. Zhang, and T. Masumoto, Mater. Trans., JIM 31, 177 (1990).

${ }^{2}$ A. Peker and W. L. Johnson, Appl. Phys. Lett. 63, 2342 (1993).

${ }^{3}$ X. H. Lin and W. L. Johnson, J. Appl. Phys. 78, 6514 (1995).

${ }^{4}$ I.-R. Lu, G. Wilde, G. P. Gorler, and R. Willnecker, J. Non-Cryst. Solids 250-252, 577 (1999).

${ }^{5}$ A. J. Drehman and A. L. Greer, Acta Metall. 32, 323 (1984).

${ }^{6} \mathrm{~N}$. Nishiyama and A. Inoue, Acta Mater. 47, 1487 (1999).

${ }^{7}$ T. D. Shen and R. B. Schwarz, Appl. Phys. Lett. 75, 49 (1999).

${ }^{8}$ J. Schroers, Y. Wu, and W. L. Johnson, Philos. Mag. A 82, 1207 (2002).

${ }^{9}$ X. H. Lin, W. L. Johnson, and W. K. Rhim, Mater. Trans., JIM 38, 473 (1997).

${ }^{10}$ Y. J. Kim, R. Busch, W. L. Johnson, A. J. Rulison, and W. K. Rhim, Appl. Phys. Lett. 68, 1057 (1996).

${ }^{11}$ C. C. Hays, J. Schroers, U. Geyer, S. Bossuyt, N. Stein, and W. L. Johnson, J. Metastable Nanocryst. Mater. 8, 103 (2000).

${ }^{12}$ W. K. Rhim, S. K. Chung, D. Barber, K. F. Man, G. Gutt, A. Rulison, and R. E. Spjut, Rev. Sci. Instrum. 64, 2961 (1993).

${ }^{13}$ A. J. Rulison, W. K. Rhim, R. Bayuzick, W. Hofmeister, and C. Morton, Acta Mater. 45, 1237 (1997).

${ }^{14}$ V. P. Skripov, in Current Topics in Materials Science, Crystal Growth and Materials, edited by E. Kaldis and H. Scheel (North Holland, Amsterdam, 1977), Vol. 2, p. 328.

${ }^{15}$ J. Schroers, R. Busch, and W. L. Johnson, Appl. Phys. Lett. 76, 2343 (2000).

${ }^{16}$ Metals Handbook, 10th ed. (ASM International, 1990), Vol. 2, p. 667.

${ }^{17}$ S. Mukherjee, J. Schroers, Z. Zhou, W. L. Johnson, and W. K. Rhim (unpublished).
} 